AR-RIHLAH: JURNAL KEUANGAN DAN PERBANKAN SYARIAH

Vol. 01, No. 01 Maret 2021, hlm. 35-45

Available at https://jurnal.unsur.ac.id/ar-rihlah/index

\title{
PERAN BMT EL-MIZAN ANNAFII \\ DALAM MENINGKATKAN KUALITAS USAHA MIKRO
}

${ }^{1}$ Dadang Yudih, ${ }^{2}$ Cahya Muthia Sharah, ${ }^{3}$ Mira Nursamsiah

1,2,3 Fakultas Ekonomi dan Bisnis Islam,Universitas Suryakancana dadangyudih@unsur.ac.id, cahyam.sharah@gmail.com,

miranursamsiah8155@gmail.com

\begin{tabular}{l|l|l} 
Masuk: Januari 2021 & Penerimaan: Februari 2021 & Publikasi: Maret 2021
\end{tabular}

\begin{abstract}
ABSTRAK
Penelitian ini bertujuan untuk menganalisa peran aktif koperasi syariah dalam meningkatkan kualitas usaha mikro dan mengetahui jenis-jenis peranan koperasi syariah dalam meningkatkan kualitas usaha mikro. Metode penelitiannya adalah metode kualitatif dengan pengambilan data melalui wawancara terstruktur, observasi lapangan dan dokumentasi. Hasil dari penelitian memperlihatkan bahwa BMT EL-MIZAN ANNAFII telah menjalankan perannya secara umum sebagai koperasi syariah yang mampu membuat kegiatan ekonomi dan sosial anggotanya yang merupakan warga sekitar masjid menjadi lebih baik dan sejahtera, sedangkan jenis-jenis peran aktif yang telah dilakukan oleh BMT EL-MIZAN ANNAFII dalam peningkatan kualitas usaha mikro hanya pada aspek fisik pemasaran produk (toko dan kerjasama dengan muslimah center) dan belum menyentuh aspek manajemen pemasaran jasa (kualitas pelayanan), manajemen produksi barang, manajemen keuangan, akuntansi sederhana, manajemen SDM dan etika bisnis syariah.
\end{abstract}

Kata Kunci : Syariah Kualitas Usaha Mikro

\begin{abstract}
This research aims to analyze the role of active Islamic cooperative in improving the quality of the micro enterprise and know the kinds of cooperative role of Sharia in improving quality of micro enterprises.Qualitative research methods are methods with data retrieval through structured interviews, field observations and documentation.The results of the research show that the BMT EL-MIZAN ANNAFII has run its role in General as a cooperative of Sharia that are able to make economic and social activities of its members which is the community around the mosque became a better and prosperous, while the types of initiatives that have been undertaken by the BMT EL-MIZAN ANNAFII in the improved quality of micro enterprises only on the physical aspects of the marketing of products and haven't touched aspects of marketing management services (quality of service), production management, financial management, simple accounting, human resource management and business ethics.
\end{abstract}

Keywords : Sharia Micro Business Quality 


\section{A. PENDAHULUAN}

Perekonomian di Indonesia sebenarnya menganut prinsip kebersamaan atau gotong-royong dengan cara saling membantu satu sama lain. Kenyataan tersebut tercantum dalam Pasal 33 UUD 1945 ayat 1 yang berbunyi, perekonomian disusun sebagai usaha bersama berdasarkan azas kekeluargaan. Perwujudan kegiatan perekonomian berdasarkan azas kekeluargaan tersebut adalah koperasi.

Koperasi sendiri berasal dari bahasa Inggris, dari kata co-operation yang artinya bekerja sama. Menurut kamus besar bahasa Indonesia, koperasi merupakan perserikatan yang bertujuan untuk memenuhi keperluan anggotanya dengan cara menjual barang keperluan sehari-hari dengan harga murah.

Sehingga keberadaan koperasi sangat tepat guna membantu perekonomian penduduk yang berpendapatan rendah. Selain itu, keberadaan koperasi juga dapat mendukung sektor-sektor informal yang saat ini banyak digeluti oleh sebagian besar penduduk Indonesia. Jumlah penduduk Indonesia berdasarkan hasil Survei Penduduk Antar Sensus (SUPAS) 2015 jumlah penduduk Indonesia pada tahun 2019 sebanyak 267 juta jiwa, sedangkan untuk tahun diproyeksikan meningkat ke 269,6 juta jiwa. Jumlah penduduk miskin pada September 2019 sebesar 24,79 juta jiwa. Umumnya masyarakat yang tergolong miskin ini lebih banyak bekerja pada sektor informal. Pertumbuhan ekonomi Indonesia yang belum memadai menyebabkan banyak penduduk yang bekerja di sektor informal (Wijono, 2005).

Pertumbuhan ekonomi yang terjadi di Indonesia tidak berdampak signifikan terhadap meningkatnya lapangan kerja. Hal tersebut dikarenakan sektor produksi yang berkembang menggunakan teknologi maju yang menggantikan tenaga kerja. Selain itu, pesatnya arus urbanisasi juga sangat mempengaruhi keberadaan sektor informal. Hal ini disebabkan para urban tersebut umumnya memiliki keterampilan dan pendidikan yang minim, sehingga mereka sulit mendapat pekerjaan yang diharapkan di sektor formal. Umumnya mereka bergelut di sektor informal seperti usaha mikro kecil dan menengah dan lain sebagainya.

Usaha mikro kecil dan menengah (UMKM) merupakan sektor ekonomi mikro yang banyak dijalankan oleh sebagian besar penduduk Indonesia baik dibantu oleh buruh atau tidak. Berdasarkan data-data dari Kementerian Koperasi dan Usaha Mikro Kecil Menengah, data pada 2019 menunjukkan bahwa kontribusi 
usaha mikro ini sangat besar dari sisi pangsa pasar. Menurut sekretaris kementrian koperasi dan UKM, Rully Indrawan mengemukakan jumlah umk saat ini mencapai 99,7\% dengan sumbangan terhadap PDB (Produk Domestik Bruto) mencapai $60,34 \%$. Sementara kontribusi terhadap total tenaga kerja sebesar 97\%. Tentu saja hal ini dapat membantu mengurangi angka pengangguran. Sedangkan kontribusi ekspor sekitar 14,17\% (Arifin, 2003).

Meskipun usaha mikro memiliki kontribusi terbesar terhadap PDB secara keseluruhan, namun serapan tenaga kerjanya masih lebih rendah dibandingkan usaha besar yang berada pada peringkat teratas dalam hal serapan tenaga kerja.

Kinerja ekspor usaha mikro masih tergolong rendah yaitu hanya mampu menyumbang Rp 16 Triliun (1,38\%), dari keseluruhan ekspor secara nasional. Hal tersebut masih jauh dibandingkan dengan kontribusi usaha besar yang mampu menyumbang Rp 979,2 Triliun (84,32\%) disusul oleh usaha menengah 134,1 Triliun (11,54\%) dan usaha kecil Rp 32,1 Triliun (2,76\%). Fakta tersebut menunjukkan bahwa usaha mikro memiliki banyak aspek kelemahan diantaranya daya saing produk yang rendah, keterampilan, kapasitas pengetahuan dan produktivitas SDM, permodalan, dan keterbatasan jaringan pemasaran (Hirsanuddin, 2008).

Menyadari kenyataan tersebut, maka perekonomian Indonesia yang berlandaskan kekeluargaan sangatlah tepat untuk menjadi mitra pendamping usaha mikro. Koperasi sebagai bentuk pengejawantahan prinsip keadilan sosial perlu berperan aktif dalam meningkatkan kualitas usaha mikro. Apalagi koperasi yang berlandaskan aturan syariah, pasti lebih menonjolkan sisi altruisme atau semangat mengedepankan kepentingan umum atau menjunjung tinggi keadilan sosial.

Koperasi merupakan lembaga ekonomi yang bertujuan untuk kesejahteraan bersama. Khususnya koperasi syariah yang dibangun atas dasar prinsip ketuhanan, persaudaraan dan keadilan harus memiliki peran dan kepedulian yang signifikan dalam meningkatkan kesejahteraan bagi anggotanya yang menjalankan usaha.

Koperasi syariah ini berhimpun dengan tujuan mengentaskan kemiskinan. Pelaku usaha mikro yang menjadi anggota koperasi umumnya adalah mereka yang tergolong ekonomi lemah, sehingga hanya mampu menjalankan usaha berskala 
mikro. Untuk itu peran koperasi sangat diperlukan dalam peningkatan kualitas usaha anggotanya yang berstatus mikro.

Berdasarkan latar belakang tersebut maka diperoleh perumusan masalah dalam penelitian ini yaitu apakah koperasi syariah berperan aktif dalam meningkatkan kualitas usaha mikro dan peran apa saja saja yang telah dilakukan oleh koperasi syariah dalam meningkatkan kualitas usaha mikro?

Dengan demikian tujuan penelitian ini adalah untuk mengetahui peran aktif koperasi syariah BMT EL-MIZAN ANNAFII dalam meningkatkan kualitas usaha mikro dan jenis-jenis peran apa yang telah dilakukan oleh Koperasi syariah BMT EL-MIZAN ANNAFII dalam meningkatkan kualitas usaha mikro anggotanya.

\section{B. METODE PENELITIAN}

Jenis penelitian ini adalah penelitian kualitatif. Menurut (Sugiyono, 2012), metode penelitian kualitatif dapat diartikan sebagai metode penelitian yang berlandaskan pada filsafat postpostivisme, digunakan untuk meneliti pada kondisi obyek yang alamiah (lawan dari eksperimen), dimana penelitian adalah instrumen utama, pengambilan data dilakukan secara purposive atau snow ball, teknik pengumpulan data dengan triangulasi, analisa data bersifat induktif dan hasil penelitian lebih menekankan makna daripada generalisasi.

Lokasi penelitian adalah koperasi syariah BMT EL-MIZAN ANNAFII yang berada di Jalan Cilaku Kampung Ciawitali Rt. 06 Rw. 02 Desa Cikaroya Kecamatan Warungkondang Kabupaten Cianjur. Dipilihnya koperasi syariah BMT EL-MIZAN ANNAFII karena koperasi syariah ini berbasis syariah dan menjalankan simpan pinjam kepada para anggotanya. Metode pengambilan data dilakukan dengan dua cara yakni, pengambilan data primer yang dilakukan dengan terjun langsung ke lapangan menemui sumber-sumber informan, yaitu wawancara, observasi lapangan dan dokumentasi. Pengambilan data sekunder dilakukan melalui studi pustaka dan mengumpulkan dokumentasi tentang koperasi syariah BMT EL-MIZAN ANNAFII.

Populasi dalam penelitian kualitatif adalah situasi sosial yang terdiri atas 3 elemen menurut Spradley dalam Sugiyono (2010), yaitu : tempat, pelaku dan aktivitas. Dengan demikian populasi atau situasi sosial yang dimaksud dalam 
peneltian ini adalah tempat penelitian yang berada di koperasi syariah BMT ELMIZAN ANNAFII di Cianjur, peneliti sebagai pelaku penelitian dan pengelola koperasi syariah BMT EL-MIZAN ANNAFII sebagai obyek penelitian serta aktivitas wawancara dan observasi lapangan yang dilakukan oleh peneliti terhadap pengelola koperasi syariah. Sedangkan teknik pengambilan sampelnya adalah dengan teknik pengambilan sampel purposive sampling, yaitu teknik pengambilan sampel melalui pemilihan sumber data dengan pertimbangan tertentu, dimana pertimbangan tertentu yang dimaksud yaitu pengambilan data langsung dari pengelola koperasi syariah BMT EL-MIZAN ANNAFII yang dianggap paling memahami gambaran pelaku usaha mikro dan berbagai pendekatan-pendekatan atau upaya-upaya apa saja yang selama ini telah dijalankan dalam meningkatkan kualitas usaha mikro di lapangan.

\section{HASIL DAN PEMBAHASAN}

Koperasi syariah adalah bentuk payung hukum yang melandasi kegiatan operasional BMT (Baitul Maal wa Tanwil). BMT adalah lembaga keuangan mikro yang dioperasikan dengan prinsip bagi hasil, menumbuh kembangkan bisnis usaha mikro dan kecil, dalam rangka mengangkat derajat dan martabat serta membela kepentingan kaum ekonomi lemah (Husaeni \& Dewi, 2019). BMT adalah lembaga bisnis yang memperoleh keuntungan tetapi juga memiliki komitmen yang kuat untuk membela kaum yang lemah dalam penanggulangan kemiskinan (Aziz, 2005).

Pada dasarnya kehadiran BMT atau biasa dikenal dengan koperasi syariah bertujuan mulia yaitu membantu masalah keuangan bagi kalangan masyarakat bawah dengan sistem syariah Islam (Sobana \& Husaeni, 2019). Namun, meskipun memiliki tujuan mulia, sayangnya tidak banyak koperasi yang berlandaskan sistem syariah di Cianjur, Jawa Barat. Salah satu BMT yang dijadikan obyek dalam penelitian ini adalah BMT EL-MIZAN ANNAFII yang berada di Jalan Cilaku Kampung Ciawitali Rt. 06 Rw. 02 Desa Cikaroya Kecamatan Warungkondang Kabupaten Cianjur, Jawa Barat. Terdapat daya tarik khusus yang melatar belakangi pemilihan BMT EL-MIZAN ANNAFII sebagai obyek penelitian ini yaitu kehadiran Koperasi syariah EL-MIZAN ANNAFII (Ridwan, 2006). 
BMT adalah Baitul maal wat tamwil. Istilah baitul maal wat tamwil berasal dari khasanah peradaban islam yang terdiri dari baitul maal dan baitul tamwil. secara etimalogis pengertian baitul maal adalah rumah harta(sosial), sedangkan baitul tamwil adalah rumah niaga/pengembangan harta (Reksa Jayengsari, 2021). BMT Merupakan salah satu bentuk dari lembaga keungan mikro bukan bank yang beroperasi berdasarkan prinsip-prinsip syariah islam (untuk selanjutnya disebut syariah) (Husaeni \& Dew, 2019).

BMT El-Mizan Annafii berdiri dan mulai beropesional pada tanggal 1 september 2009 dengan alamat Kp. Cibening Desa Cisarandi Kecamatan Warungkondang Kabupaten Cianjur. Jumlah anggota terdiri dari 20 orang, dengan ketua Ir. Diah Elviany, Bendahara Wardania Puperta, Sekertaris Popy Aprilianti dengan pengawas Deni Adriadi Gunawan SE dan anggota pengawas Syamsudin.

KJKS (Koperasi Jasa Keuangan Syariah) BMT El-Mizan Annafii sudah tercatat dengan SK Badan Hukum 1188/BH-DK/XII.6/B.KOP/2009 (Dinas Koperasi UMKM di Cianjur). Tanggal 16 Februari 2009 yang telah disesuaikan dengan UU NO. 25 Tahun 1992 tentang pengkoperasian. Dengan akta pendirian No. 08 tanggal 26 November 2008 dan akta perubahan No. 06 tanggal 06 Agustus 2009 dengan nomor badan hukum.

Pada tahun 2013 kantor pusat BMT El-Mizan Annafii pindah ke Jl. Raya Cilaku Kp. Ciawitali Desa Cikaroya Kecamatan Warungkondang Kabupaten Cianjur. BMT El-Mizan Annafii mengganti namanya dengan KSPPS (Koperasi Simpan Pinjam Pembiayaan Syariah) El-Mizan pada tanggal 1 Januari 2016 dikarnakan peraturan dari Kementrian Koperasi.

Adapun tujuan BMT El-Mizan Annafii didirikan adalah untuk mengedukasi masyarakat dan meminimalisir kegiatan bank keliling yang mengandung unsur riba dengan menyerukan masyarakat umum khususnya anggotanya untuk membiasakan melakukan kegiatan simpan pinjam berdasarkan sistem syariah melalui BMT ElMizan Annafii. Melalui pemberdayaan ekonomi dan peningkatan kesejahteraan khususnya di kalangan usaha mikro kecil melalui sistem syariah, meningkatkan semangat dan peran anggota masyarakat dalam kegiatan jasa keuangan syariah dan menggalang dana bagi pengembangan dan operasionalisasi BMT El-Mizan Annafii supaya berkinerja baik, amanah dan professional (Azis, 1999). 
Misinya adalah menjadi koperasi simpan pinjam syariat yang tumbuh sehat, berkembang dan terpercaya yang mampu melayani anggotanya dan masyarakat lingkungannya, untuk mencapai kehidupan yang sejahtera, melakukan kegiatan simpan pinjam secara syariah bagi anggotanya dengan mengutamakan pelayanan pada usaha mikro berbagai sector informasi guna menunjang kegiatan ekonomi rakyat kecil dan membebaskan dari praktek ribawi, memberikan pelayanan prima kepada anggotanya dan didukung dengan sumber daya insani, yang professional dengan melaksanakan syariat Islam, memberikan keuntungan baik sosial maupun finansial yang optimal bagi stake holder (anggota, calon anggota, pengurus, masyarakat, dan pemerintah.

Sedangkan visinya adalah menjadi koperasi simpan pinjam syariat yan tumbuh sehat, berkembang, dan terpercaya. Yang mampu melayani anggotanya daan masyarakat lingkungannya untuk mencapai kehidupan yang sejahtera. Produk-produk yang ditawarkan sama seperti koperasi jasa keuangan syariah pada umumnya yaitu mudharabah, murabahah, dan ijarah.

Sebagaimana diketahui bahwa peranan koperasi syariah secara umum menurut Aziz (2005) adalah bahwa BMT merupakan motor penggerak ekonomi dan sosial masyarakat banyak, ujung tombak pelaksanaan ekonomi syariah, penghubung antara kaum berada (aghniya) dan kaum yang lemah (dhuafa) serta sarana pendidikan informal untuk mewujudkan prinsip hidup melalui spiritual communication dzikir qalbiyah ilahiah.

BMT El-Mizan Annafii berusaha meminimalisir kegiatan bank keliling yang mengandung unsur riba dengan menyerukan masyarakat umum khususnya anggotanya untuk membiasakan melakukan kegiatan simpan pinjam berdasarkan sistem syariah melalui BMT El-Mizan Annafii dengan jumlah simpanan yang sangat ringan dengan perincian simpanan pokok sebesar Rp 100.000,- per bulan, simpanan wajib Rp 10.000,- per bulan dan simpanan sukarela.

Kemudian BMT menyalurkan pembiayaan dalam bentuk akad murabahah dan mudharabah kepada para anggotanya. Kisaran pembiayaan yang disalurkan sebesar Rp 500.000,00 - Rp 5.000.000,00 untuk nasabah baru.

BMT El-Mizan Annafii menerima zakat, infak dan sedekah dari bukan anggota berupa zakat maal yang kemudian disalurkan mustahik. Dengan demkian 
fungsi BMT El-Mizan Annafii tidak hanya mengejar keuntungan semata tetapi juga membawa misi sosial menjembatan antara si kaya dan si miskin supaya bisa saling tolong-menolong. Dengan demikian BMT El-Mizan Annafii telah menjalankan perannya secara umum sebagai koperasi syariah yang mampu membuat kegiatan ekonomi dan sosial anggotanya yang merupakan warga sekitar menjadi lebih baik dan sejahtera.

Terdapat beberapa ciri-ciri usaha yang dilakukan pelaku usaha kecil dan mikro berdasarkan kajian yang dilakukan oleh Bank Indonesia (2015) bahwa usaha mikro memiliki karakteristik sebagai berikut: kualitas produk yang belum memiliki standar karena keterbatasan pengetahuan, ketersediaan bahan baku yang tidak kontinyu dan tidak terjamin, bahan baku kurang terstandar dan lain-lain, belum melakukan administrasi keuangan sederhana sekalipun, sumber daya manusia belum memiliki jiwa wirausaha yang memadai, tingkat pendidikan rata-rata relatif rendah, umumnya tidak memiliki izin usaha atau persyaratan legalitas lainnya seperti NPWP, Contoh usaha perdagangan seperti pedagang kaki lima atau pedagang di pasar. Jenis usaha yang digolongkan mikro adalah jenis usaha yang memiliki aset maksimal Rp 50 juta dengan omset Rp 100 juta.

Berdasarkan penelitian Prasad dan Tata (2009), bahwa perbaikan kualitas akan membuat usaha mikro menjadi lebih kompetitif. Kualitas yang dimaksud oleh Prasad dan Tata dalam penelitian tersebut adalah terhubungnya usaha mikro dengan informasi berupa akses pasar, link, sumber hukum dan sumber daya ekonomi.

Sedangkan Nag dan Das (2015) membuat konsep pelatihan khusus untuk usaha mikro yang bertujuan tidak hanya meningkatkan skill berwirausaha pelaku usaha mikro, tetapi juga pelatihan yang mengandung unsur berupa petunjukpetunjuk tentang bagaimana usaha mikro tetap langgeng. Konsep Nag dan Das sangat komprehensif yang meliputi pengetahuan- pengetahuan di bidang soft skill berwirausaha seperti kreatifitas, kepemimpinan, etika bisnis dan lain-lain, bidang manajemen antara lain pemasaran, SDM, produksi, keuangan serta pengetahuan akses permodalan ke lembaga bank dan non bank.

Bekerjasama dengan Bank BNI yang berfungsi sebagai unit layanan dan juga sebagai upaya membangun link dengan masyarakat di wilayah yang berbeda. Meminta agar anggota selalu disiplin dan tertib administrasi dengan menyisihkan 
keuntungan yang diperoleh melalui tabungan di rumah supaya setiap tanggal jatuh tempo pembayaran dapat melakukan pengembalian pinjaman atau pembiayaan.

Secara kualitas dan kuantitas BMT El-Mizan Annafii telah mampu meningkatkan kualitas usaha mikro anggotanya yang dicirikan dengan peningkatan keuntungan yang diperoleh setiap tahunnya yang dibagikan dalam bentuk Sisa Hasil Usaha (SHU). Selama tahun 2019, keuntungan yang diperoleh di bawah sebesar Rp 87.316.125, 72,- .

Namun demikian upaya-upaya tersebut belum bisa dikatakan optimal karena masih terdapat karakteristik lain dari usaha mikro yang belum bisa ditangani oleh BMT El-Mizan Annafii seperti melakukan penyuluhan manajemen berwirausaha yang baik sehingga terjadi peningkatan omzet usaha. Peningkatan kualitas usaha mikro dicirikan dengan meningkatnya omset usaha sehingga bisa meningkat menjadi jenjang usaha kecil. Meningkatnya omzet tidak hanya dengan menghubungkan produk barang yang dibuat dengan akses dan link pasar yang lebih luas tetapi lebih jauh dari itu pelaku usaha perlu diberikan pengetahuan pendukung seperti bagaimana memenuhi kepuasan konsumen. Kepuasan konsumen hanya bisa diwujudkan apabila produk yang ditawarkan mampu melebihi harapan konsumen terhadap nilai produk yang dijual tersebut. Dengan demikian BMT El-Mizan Annafii perlu membuat program pelatihan dan penyuluhan yang terjadwal tentang pelatihan ketrampilan manajemen berwirausaha yang tepat seperti bagaimana menjaga kualitas produk dan bahan baku, kontinuitas bahan baku, jaminan mutu barang yang sudah terstandarisasi misalnya memperoleh stempel halal dari MUI, diakui oleh BPOM dan memperoleh pengakuan SNI bahkan ISO.

Tahap peningkatan kualitas usaha yang dilakukan oleh BMT El-Mizan Annafii baru pada langkah awal dan sederhana yaitu bagaimana menjauhkan masyaraakat dari riba (dakwah). Secara ringkas Tabel 2 berikut ini memperlihatkan tindakan-tindakan yang telah dan belum dilakukan oleh BMT El-Mizan dalam peningkatkan kualitas usaha mikro anggotanya: 
Tabel 1 Tindakan yang Telah dan Belum Dilakukan oleh BMT El-Mizan Annafii dalam Peningkatan Kualitas Usaha Mikro Anggotanya

\begin{tabular}{|l|l|}
\hline No & \multicolumn{1}{|c|}{ Tindakan-tindakan } \\
\hline 1. & $\begin{array}{l}\text { Mengedukasi masyarakat agar terhindar dari bank } \\
\text { keliling }\end{array}$ \\
\hline 2. & Mengedukasi masyarakat agar mengikuti prosedur \\
\hline 3. & $\begin{array}{l}\text { Membiayai usaha mikro masyarakat dikalangan bawah } \\
\text { sampai menengah }\end{array}$ \\
\hline 4. & $\begin{array}{l}\text { Meningkatkan kesejahteraan bersama melalui kegiatan } \\
\text { ekonomi yang menaruh perhatian pada nilai-nilai dan } \\
\text { kaidah-kaidah muamalah yang memegang keadilan, } \\
\text { keterbukaan dan kehati-hatian . }\end{array}$ \\
\hline
\end{tabular}

\section{SIMPULAN}

BMT El-Mizan Annafii sebagai koperasi syariah di bidang jasa keuangan telah menjalankan peranan koperasi syariah pada umumnya yaitu sebagai motor penggerak kegiatan ekonomi dan sosial masyarakat, ujung tombak pelaksanaan ekonomi syariah, penghubung si kaya dan si miskin dan sarana pendidikan informal.

BMT El-Mizan Annafii sebagai Koperasi syariah menyeimbangkan unsur sosial, agama dan ekonomi masyarakat sekitar yang artinya BMT El-Mizan Annafii tidak semata-mata mengejar keuntungan ekonomi tetapi juga membantu kehidupan sosial dan agama. Karena BMT El-Mizan Annafii melakukan kegiatan dakwah sekaligus berbisnis. Kehadiran BMT El-Mizan Annafii sebagai koperasi syariah perlu didorong peningkatannya dengan cara menambah permodalannya melalui kerjasama dengan bank-bank besar syariah supaya peran aktif BMT dapat lebih ditingkatkan karena BMT El-Mizan Annafii sangat bermanfaat membantu meningkatkan kehidupan sosial, agama dan ekonomi masyarakat sekitar menjadi lebih baik dan sejahtera. Meningkatkan kinerja dan operasional menjadi lebih baik dengan menambah sumber daya insani yang akan membantu meningkatkan kinerja 
BMT El-Mizan Annafii secara umum, khususnya dalam meningkatkan kualitas usaha mikro anggotanya.

\section{REFERENSI}

Arifin, Z. (2003). Dasar-dasar Manajemen Bank Syariah. AlvaBelt.

Azis, M. A. (1999). Pedoman Penilaian Kesehatan BMT (Baitul Maal wat Tamwil). PINBUK.

Hirsanuddin. (2008). Hukum Perbankan Syariah di Indonesia (Pembiayaan Bisnis Dengan Prinsip Kemitraan). Genta Press.

Husaeni, U. A., \& Dew, T. K. (2019). The dynamics of the development of baitul maal wa tamwil in Indonesia with the swot analysis approach. International Journal of Scientific and Technology Research, 8(8), 1678-1685.

Husaeni, U. A., \& Dewi, T. K. (2019). Pengaruh Pembiayaan Mikro Syariah Terhadap Tingkat Perkembangan Usaha Mikro Kecil Menengah (Umkm) Pada Anggota Bmt Di Jawa Barat. Bongaya Journal for Research in Management (BJRM), 2(1), 48-56. https://doi.org/10.37888/bjrm.v2i1.122

Reksa Jayengsari, U. A. H. (2021). the Role of Baitul Maal Wa Tamwil in Alleviating Poverty in Cianjur Regency, West Java. Jurnal Ekonomi Dan Keuangan Syariah, 5(1), 56-66.

Ridwan, M. (2006). Sistem dan Prosedur Pendirian Baitul Maal wat Tamwil (BMT). Citra Media.

Sobana, D. H., \& Husaeni, U. A. (2019). Economic Empowerment of Poor Women With Grameen Bank Patterns on Baitul Mal Wa Tamwil Ibadurrahman. International Journal of Islamic Economics and Finance Studies, 40-59. https://doi.org/10.25272/ijisef.450600

Sugiyono. (2012). Metode Penelitian Kuantitatif Kulalitatif dan R\&D, Bandung. Alfabeta.

Wijono, W. W. (2005). Pemberdayaan Lembaga Keuangan Mikro Sebagai Salah Satu Pilar Sistem Keuangan Nasional: Upaya Konkrit Memutus Mata Rantai Kemiskinan.

Marjudin, Berkontribusi Besar Terhadap PDB, UMKM Banyak Temui Kendala, https://www.indopremier.com/ipotnews/newsDetail.php?jdl=Berkontribusi _Besar_Terhadap_PDB_UMKM_Banyak_Temui_Kendala\&news_id=108 $857 \&$ group_news $=$ IPOTNEWS\&news_date $=\&$ taging_subtype $=$ ECONO MIS\&name=\&search=y_general\&q=UMKM,\%20Koperasi,\&halaman=1, diunduh pada jumat, 06 November 2020 pukul 10.00 WIB.

Persentase Penduduk Miskin September 2019 Turun Menjadi 9,22 Persen, https://www.bps.go.id/pressrelease/2020/01/15/1743/persentase-pendudukmiskin-september-2019-turun-menjadi-9-22-persen.html, diunduh pada jumat, 06 November 2020 pukul 11.00 WIB. 